\title{
Surface roughened zirconia: towards hydrothermal stability
}

\author{
Erik Camposilvan $^{1,2, *}$, Quentin Flamant ${ }^{1,2}$ and Marc Anglada ${ }^{1,2}$ \\ ${ }^{1}$ Department of Materials Science and Metallurgical Engineering, \\ Universitat Politècnica de Catalunya, Av. Diagonal 647, 08028 Barcelona - Spain \\ ${ }^{2}$ Center for Research in NanoEngineering CRnE, Universitat Politècnica de Catalunya, Av. Diagonal 647, \\ Barcelona, 08028, Spain \\ * Corresponding author \\ E-mail: erik.camposilvan@upc.edu \\ Phone number: +34 934054452 \\ Fax number: + 34934016706
}

\begin{abstract}
Surface roughness is needed in several yttria-stabilized zirconia components used in restorative dentistry for osseointegration or adhesion purposes. This can be achieved by different treatments, which may also modify the microstructure of the surface. Among them, sandblasting and chemical etching are widely used, but their effect on hydrothermal aging of zirconia is not fully understood. In the present work, the zirconia long-term stability of rough surfaces prepared by these techniques is analyzed and a method is proposed for preventing hydrothermal aging while maintaining the original surface appearance and mechanical properties. The method involves pressure infiltration of a Cerium salt solution on the roughened surfaces followed by a thermal treatment. The solution, trapped by surface defects and small pores, is decomposed during thermal treatment into Cerium oxide, which is diffused at high temperature, obtaining Ce co-doping in the near-surface region. In addition, the microstructural changes induced in the near-surface by sandblasting or chemical etching are removed by the thermal treatment together with surface defects. No color modification was observed and the final roughness parameters were in the range of existing implants of proved good osseointegration. The aging resistance of Ce co-doped materials was strongly enhanced, showing the absence of aging after artificial degradation, increasing in this way the surface mechanical integrity.

The proposed treatment is easily applicable to the current manufacturing procedures of zirconia dental posts, abutments, crowns and dentures, representing a solution to hydrothermal aging in these and other biomedical applications.
\end{abstract}

Keywords: Infiltration, Zirconia, Low temperature degradation, Sandblasting, Osseointegration, Acid etching, Dental implant, Dental crown. 


\section{Introduction}

In the last decade, yttria-stabilized zirconia ceramics have been progressively occupying a more relevant role in restorative dentistry, thanks to their superior strength, moderate fracture toughness and biocompatibility (Denry and Kelly, 2008). These mechanical properties are associated to the sub-micrometric grain size and to the transformation toughening mechanism. The tetragonal phase, retained at room temperature in a metastable state thanks to the presence of 3 mol\% of Yttrium oxide, can transform into the stable monoclinic phase under the local tensile stress at the tip of a crack under loading. The transformation is accompanied by an increase in volume of about $4.5 \%$, and since it is constrained by the surrounding elastic material, compressive stresses are induced, which enhance the crack propagation resistance (transformation toughening) (Garvie et al., 1975). The good combination of fracture toughness and strength of 3Y-TZP allows its employment in a series of applications, which include dental crowns, dental implants, abutments, orthodontic brackets and fixed partial dentures (FPD’s) (Conrad et al., 2007; Denry and Kelly, 2008; Kelly and Denry, 2008).

The main limitation of zirconia is represented by low temperature degradation (LTD), also known as hydrothermal degradation or aging. It consists in the spontaneous transformation of the surface to the monoclinic phase in humid environments and moderate temperatures, including human body conditions (Chevalier et al., 2007). LTD is slow at room temperature and interests only a superficial layer of few micrometers in well-densified 3Y-TZP, but it is accompanied by the formation of surface microcracks, surface roughening and loss of cohesion, making the material unsuitable for orthopedic joint replacement where surface stability is fundamental.

Sandblasting is a treatment that is commonly applied in the manufacturing of zirconia dental crowns in order to increase the surface area and roughness. This, in turn, promotes the adhesion between the crown and either the luting cement or the veneering porcelain, by increasing wettability, surface energy and the bonding area (Fischer et al., 2008; Kern and Wegner, 1998; Wolfart et al., 2007).

Roughness is created through an erosive wear process in which high-speed hard particles impact on the surface and chunks of material are removed. During the impact, local surface plastic deformation and subsurface cracks may be generated. Lateral cracks, parallel to the surface, contribute to the erosion process, whereas radial cracks, perpendicular to the surface, may impair the material performance (Lawn, 1993). 
During mechanical modification of the surface by sandblasting, local phase transformation may take place, which may induce damage as well as compressive forces as a result of the local volume increase associated with the transformation. The sole sandblasting may increase or decrease the strength depending on the tradeoff between the effect of the surface compressive layer resulting from the process and the characteristics of the additional surface defects introduced (Chintapalli et al., 2014; Kosmač, 2008). It is important to underline that the compressive stresses disappear if a heat treatment is performed after sandblasting, as it happens during the veneering process, due to reconversion of the monoclinic layer and stress release. As a result, the superficial cracks are exposed to tensile stresses, lowering the strength. It was shown that the optimization of sandblasting parameters allows generating lower damage during the process, limiting the strength decrease associated to the thermal treatment (Chintapalli et al., 2014).

Sandblasting delays the beginning and lowers the kinetics of LTD. Since the aging behavior of zirconia of sandblasted plus annealed specimens is similar to sintered plus polished specimens, the lower LTD in the sandblasted state must be related to the superficial compressive layer and the local plastic deformation generated. (Chintapalli, 2012; Kim et al., 2010; Kosmač, 2008). Nevertheless, specimens obtained maximizing the strength by choosing optimum sandblasting conditions, may suffer a drop in strength after artificial degradation, being the drop severe after long and aggressive aging treatments (Chintapalli, 2012; Kosmač, 2008; Papanagiotou et al., 2006).

Chemical etching has been reported to be an efficient technique to produce a fine roughness on zirconia, down to the nanoscale (Hempel et al., 2010). Gahlert et al. evidenced that hydrofluoric acid (HF) etching of zirconia implants enhances bone apposition resulting in high removal torque values (Gahlert et al., 2010). Other chemicals, such as hypophosphorous acid or an equimolar mixture of potassium hydroxide and sodium hydroxide, have been reported to successfully etch Y-TZP (Casucci et al., 2010; Gruber et al., 2012). However, HF presents the advantage to be a fast etchant at room temperature.

In recent studies, it was shown that by introducing surface roughness in 3Y-TZP, the cell response was similar to titanium and alumina, concluding that roughened zirconia surface represents an appropriate substrate for proliferation and spreading of osteoblastic cells (Bächle et al., 2007; Wenz et al., 2008; Yamashita et al., 2009). It was also reported that zirconia dental implants with acid etched surface (CeraRoot implants with 
ICE $^{\mathrm{TM}}$ surface) showed a similar or higher success rate as for Titanium implants after 5 years of follow-up study (Oliva et al., 2010).

Besides, Cooper et al. (Cooper et al., 2006) found that the incorporation of fluoride at the surface of titanium implants could enhance osteoblastic differentiation and interfacial bone formation. More recently, Ito et al. (Ito et al., 2013) showed that the combination of sandblasting with HF etching leads to an increase in the proliferation rate and expression of ALP activity of osteoblast-like cells (MC3T3-E1).

The stability of 3Y-TZP surface is fundamental for the performance in dental applications, since the surface is responsible for transferring the load from the veneer/luting cement to the crown/abutment or from the implant to the bone. Although water may be not directly in contact with zirconia dental crowns, it can penetrate into luting cements and have access to the material surface, which can be therefore exposed to degradation (Jevnikar et al., 2000). Therefore, hydrothermal degradation may play a role on the stability of the crown surface and finally on the life time of the part. The same situation is found in implants connected to the bone, where body fluids are always present and the role of the surface is of extreme importance. Therefore, there is a clear need for improving 3Y-TZP aging resistance and guarantee its surface stability.

Several works have proved that co-doping Y-TZP with Ce can improve substantially the degradation behavior (Boutz et al., 1995; Lin and Duh, 2003; Marro et al., 2011; Sato et al., 1987), probably due to the reduction in concentration of oxygen vacancies decreasing in this way the diffusion of water species which has been recognized as the trigger mechanism for the degradation phenomenon (Guo, 1998). In a recent work by the authors (Camposilvan et al., 2015), Ce co-doping was performed by infiltration in the pre-sintered state to increase the degradation resistance of 3Y-TZP. The process consists in the infiltration of porous pre-sintered 3Y-TZP preforms with optimized solutions containing cerium nitrates, which decompose to $\mathrm{CeO}_{2}$ and diffuse into the zirconia lattice during sintering, obtaining higher Ce concentrations in the surface region and making the co-doped material far more resistant to aging. Nonetheless, a modest reduction in the fracture toughness of the superficial region was recorded, together with a moderate reduction of the strength for $\mathrm{CeO}_{2}$ contents over 3-4 mol\% (Camposilvan et al., 2015, 2012). At the same time, when significant quantities of $\mathrm{CeO}_{2}$ are introduced with this process, the color of the specimen becomes yellowish, which represent a limitation for the application precisely in visible dental parts e.g. dental crowns. 
The infiltration processing technique is applied in this work to 3Y-TZP rough surfaces induced by either sandblasting or acid etching. This "surface infiltration" is performed on the fully sintered and roughened material, and is followed by a diffusion treatment. The aim is to study whether the superficial defects, cracks and pores present after roughening are able to retain sufficient amounts of solution so that the aging resistance of the material can be significantly improved. It is expected that the thickness of the surface modified material would be so small to not affect the mechanical and optical properties.

\section{Materials and Methods}

3Y-TZP spray-dried powders (Tosoh corp.) were isostatically pressed into cylindrical rods at $200 \mathrm{MPa}, 10$ $\min$. The green body was then sintered in air at $1450{ }^{\circ} \mathrm{C}$ in a tubular furnace with a heating/cooling ramp of $3 \% \mathrm{~min}$ and dwell time of $2 \mathrm{~h}$. During the heating segment, a dwell time of one hour was applied at $700{ }^{\circ} \mathrm{C}$ to evacuate the sintering and pressing additives. The sintered rods were cut into discs of approx. $9.5 \mathrm{~mm}$ in diameter and $2.2 \mathrm{~mm}$ in thickness and were ground (Struers MD-Piano 220) and polished with diamond pastes down to a superficial roughness of less than $0.02 \mu \mathrm{m}$ Ra. This represents the base material for our studies and is named as-sintered (“AS").

\subsection{Roughening treatments}

Sandblasting of the specimens was performed with a sandblaster "Easy Blast" (BEGO, USA) using alumina particles with a diameter of $110 \mu \mathrm{m}$, working pressure of 2 bars and projection time of $10 \mathrm{~s}$. These conditions had been previously optimized for this material and the sandblasting media employed in order to minimize the damage (Chintapalli, 2012; Chintapalli et al., 2014). The obtained samples were cleaned successively with acetone, ethanol and deionized water in an ultrasonic bath (5 min for each bath) and will be referred to as "S" for sandblasted.

The AS samples were cleaned before etching by sonication, in a similar fashion as done for the S samples for removing contaminants from the surface. Etching was performed by immersing for 1 hour zirconia disks in high-density polyethylene flasks filled with concentrated HF (Hydrofluoric Acid 40\% QP Panreac, Spain). The disks were placed with the polished side upwards. Just after being removed from the HF solution, they were rinsed in deionized water in order to stop the reaction. They were then cleaned twice during 10 min by 
sonication with deionized water in order to remove any remaining product of the reaction from the surface.

This etched and cleaned condition is labeled " $E$ ".

\subsection{Pressure infiltration}

After drying, the samples were submerged in a saturated solution of Ce(III) nitrate hexahydrated (REacton, 99.9\%, Alfa Aesar, USA) in distilled water inside a deformable mold. The mold was closed and inserted in an isostatic press and a pressure of $50 \mathrm{MPa}$ was applied during 10 minutes. After the immersion, the samples surface was quickly dried with clean laboratory paper to eliminate the solution in excess. During the drying and decomposition treatment, which was performed from 60 to $450{ }^{\circ} \mathrm{C}$ with a dwell time of $1 \mathrm{~h}$, the water from the remaining solution, trapped into surface defects, was evaporated and the precipitated salt decomposed to form Cerium oxide. After that, the specimens were thermally treated (TT) at $1450{ }^{\circ} \mathrm{C}$ in air during $1 \mathrm{~h}$ to allow the diffusion of the $\mathrm{CeO}_{2}$ from the infiltrated surface. Sets of non-infiltrated $\mathrm{S}$ and $\mathrm{E}$ samples were also thermally treated in the same way and will be referred to as ST and ET, respectively. The infiltrated and TT specimens will be instead referred to as SIT and EIT respectively. A summary of the treatments associated to each surface is presented in Table 1.

Table1. Summary of specimens preparation treatments, performed in sequence from left to right.

\begin{tabular}{|c|c|c|c|c|c|}
\hline Material & $\begin{array}{l}\text { Sint } 1450^{\circ} \mathrm{C} \\
2 \mathrm{~h}+\text { polished }\end{array}$ & $\begin{array}{l}\text { Sandblast. } \\
10 \mathrm{~s}\end{array}$ & $\begin{array}{l}\text { A. Etching } \\
1 \mathrm{~h}\end{array}$ & $\begin{array}{l}\text { Inf.50MPa } \\
10 \mathrm{~s}\end{array}$ & $\begin{array}{l}\text { TT } 1450^{\circ} \mathrm{C} \\
1 \mathrm{~h}\end{array}$ \\
\hline AS-control & $\checkmark$ & & & & \\
\hline $\mathrm{S}$ & $\checkmark$ & $\checkmark$ & & & \\
\hline ST & $\checkmark$ & $\checkmark$ & & & $\checkmark$ \\
\hline SIT & $\checkmark$ & $\checkmark$ & & $\checkmark$ & $\checkmark$ \\
\hline E & $\checkmark$ & & $\checkmark$ & & \\
\hline ET & $\checkmark$ & & $\checkmark$ & & $\checkmark$ \\
\hline EIT & $\checkmark$ & & $\checkmark$ & $\checkmark$ & $\checkmark$ \\
\hline
\end{tabular}

\subsection{Roughness characterization}

White Light Interferometry (WLI, Veeco Wyko 9300NT) was used in order to characterize the topography at different scales for the seven surfaces listed in Table 1. WLI measurements were performed on $150 \mu \mathrm{m}$ x 150 $\mu \mathrm{m}$ areas (stitching of 4 images acquired at magnification 50x, resolution: $758 \times 758$ pixels). The roughness analysis of the data from WLI was performed using Veeco's Vision® software. Tilt was corrected and a robust short wavelength pass Gaussian filter (cut-off wavelength: $10 \mu \mathrm{m}$ ) was applied to the data in order to separate 
waviness from roughness. Finally, the 3D roughness parameters described in Table 2 were determined. The results were treated statistically with one-way analysis of variance (ANOVA) with a Tukey post-hoc test, employing the software Minitab. p-value was set at 0.05 . Mean values plus standard deviations are presented in the results, while letters on the columns charts show the statistically significant differences.

Table 2. Brief description of the 3D roughness parameters studied (W. Dong et al., 1994; W. P. Dong et al., 1994).

\begin{tabular}{|c|c|c|c|}
\hline Symbol & Category & Parameter & Description \\
\hline $\mathrm{Sa}$ & Amplitude & Average roughness & Average of height values \\
\hline$S_{\mathrm{ds}}$ & Spatial & Density of summits & Number of summits per unit area \\
\hline$S_{d r}$ & Hybrid & $\begin{array}{l}\text { Developed } \\
\text { interfacial area ratio }\end{array}$ & $\begin{array}{l}\text { Percentage of additional surface area contributed by the texture } \\
\text { as compared to an ideal plane the size of the measurement region }\end{array}$ \\
\hline
\end{tabular}

\subsection{Aging studies}

For testing the aging behavior after the different surface treatments, the samples were exposed to artificial degradation in autoclave under water vapor at $134^{\circ} \mathrm{C}$ and 2 bar pressure for $30 \mathrm{~h}$. This time was chosen to represent more than the expected life of the application, since it corresponds roughly with 60 years in vivo (Chevalier et al., 1999). After the treatment, the monoclinic phase volume fraction (Vm\%) near the surface was measured with XRD by applying the equation of Toraya et al. (Toraya et al., 1984) and results were analyzed as in the previous section. This is a good indicator of the proneness of the material towards hydrothermal degradation.

\subsection{Hardness and surface cracks}

Hardness was measured by performing Vickers indentations with a load of $10 \mathrm{Kg}$ after artificial degradation. Smaller loads did not give reproducible results due to the non planarity of the surface, while nanoindentation could not be performed for similar reasons. The purpose of indentation tests was to evaluate the effect of thermal treatment on bulk hardness and to compare indentation-induced cracks. In fact, even though the crack depth is of at least $30 \mu \mathrm{m}$, its length and opening at the surface changes depending on the superficial stress state associated to degradation, roughening and thermal treatments. In this case, indentation fracture (IF) toughness cannot be directly compared. Instead, the ratio $c / a$ will be reported in the results as a measure of the proneness to superficial crack formation, where $c$ is the distance between the tip of the crack developing from 
the indentation corner and the indentation center and $a$ is half of the indentation diagonal. Indentation marks were imaged for measurement by laser scanning confocal microscopy (LSCM) and optical microscopy (OM) with differential interference contrast illumination (DIC). Statistical analysis was performed with the same procedure as in section 2.3.

\section{6. $\quad$ FIB - SEM - EDS characterizations}

SEM micrographs of the sandblasted and acid etched surfaces were taken with a FIB/SEM dual beam station Neon 40 (Carl Zeiss AG, Germany) after coating the surface with either carbon (sandblasted surface) or $\mathrm{Au} / \mathrm{Pd}$ (acid-etched surface) to make it conductive. Energy-dispersive X-Ray spectroscopy (EDS) was performed at $10 \mathrm{KV}$ to map the Ce distribution on the surface. FIB trenches were milled and polished from the surface of selected conditions, after depositing a strip of protective Pt, in order to observe the subsurface appearance of the material and eventually the damage induced either by the roughening or aging processes. Etched specimens were characterized in this manner before and after artificial degradation. In sandblasted samples, this characterization was performed after exposure to artificial degradation, since the non-aged state had been characterized in previous works (Chintapalli et al., 2013). EDS was performed on trenches to evaluate the thickness of the co-doped layer. It is worth mentioning that artificial aging affects only a surface layer producing microcracks and showing the formation of monoclinic laths, but the general appearance and the roughness of the sandblasted or etched specimens is not altered.

\section{Results}

\subsection{Roughness parameters}

The topographic images of the surface of EIT and SIT specimens are shown in Figure 1. The column chart of the same figure presents the variation of several roughness parameters associated to all the different material conditions. The measured average roughness, $\mathrm{S}_{\mathrm{a}}$, of $\mathrm{S}$ and $\mathrm{E}$ specimens was not significantly different, about $280 \mathrm{~nm}$. After thermal treatment, ET and ST specimens registered a decrease in roughness of $\sim 10 \%$ and $\sim 18 \%$, respectively. However, after infiltration and thermal treatment, SIT surfaces registered a further small decrease in $\mathrm{S}_{\mathrm{a}}$, while EIT showed the opposite behavior. Regarding the specific surface area of etched surfaces, it was not practically affected by infiltration, but a substantial reduction was observed after thermal 
treatment. On the other hand, the peak density was practically the same for the different treatments on sandblasted specimens, while a decrease was registered in ET and EIT with respect to E specimens. Regarding color, the aspect of all the specimens was similar, while the reflectivity was obviously changed after roughening treatments but unaltered by infiltration and thermal treatment.

\subsection{FIB/SEM characterization}

The surface appearance of S, ST and SIT specimens after artificial degradation are presented in the micrographs of Fig. 2. It can be appreciated that while the aged ST and SIT surfaces looked similar, the martensitic plates associated to the aging phenomenon were visible only in ST specimens. The grain size at the surface was slightly bigger in infiltrated samples, although this change was difficult to quantify due to non-planarity of the surface and the presence of alumina particles.

In the same figure, the EDS analysis shows that the darker particles in the SEM images were alumina fragments that had been sintered to the hosting surface during the thermal treatment. Ce mapping on the SIT samples indicates that the Ce distribution was quite uniform.

FIB images of trenches milled on the $\mathrm{S}$ surfaces right after sandblasting and on SIT specimens after artificial degradation are shown in Fig. 3. Phase transformation could be observed in S specimens, but no transformation associated with LTD could be appreciated on sandblasted specimens after infiltration and TT, meaning that the tetragonal structure was recovered during the TT and not affected by hydrothermal exposure. In the same picture, a slight increase in grain size can be sensed only for the first outer line of grains.

The superficial appearance of E, ET and EIT aged specimens was similar up to magnifications of 3000x (see Fig. 4). Further magnification shows that the high temperature treatment has an evident effect on the morphology of the etched grains and porosity at the micro- and nanometric scale. Superficial grains lose their sharp profile and become rounded, meanwhile the numerous nanometric pores, which appear after etching, merge into pores of slightly bigger size and rounded contour. After infiltration and thermal treatment, the residual porosity seems to be further reduced and the superficial grains become slightly bigger.

In Fig. 5, the FIB trenches milled on the etched specimens after different additional treatments are presented. The effect of the thermal treatment is to close almost all superficial porosity generated by the etching process. The nanometric roughness present on the etched surface become smoother and the morphology of the surface 
at the micrometric scale looks less flat. In the degraded ET specimens, a surface layer with the presence of LTD microcracks can be appreciated. Infiltrated samples had a smoother profile, meaning that the presence and diffusion of $\mathrm{CeO}_{2}$ from the surface has the effect of sealing pores and reducing asperities.

On the other hand, the integrity of the superficial rough layer appeared enhanced in infiltrated conditions. No presence of LTD microcracks was detected on the EIT aged samples. Few localized spots with evidence of degradation were instead detected only during preliminary studies in which the infiltration was performed at atmospheric pressure (see supporting information for pictures).

Individual grains can be clearly recognized in ion images, where the channeling phenomenon affects the contrast, or in SEM images after exposure to the ion beam to reveal the microstructure. From these pictures it can be appreciated that the grain growth observed in the SEM pictures taken from the top of the surface affected only the first superficial grain layer. Furthermore, the EDS results superimposed on the picture 5-E indicate that the enriched layer has a concentration of $\mathrm{Ce}>1 \mathrm{~mol} \%$ in a thickness limited to about $2 \mu \mathrm{m}$ from the surface.

\subsection{Response to indentation}

Vickers hardness and $c / a$ ratio are shown in Fig. 6. Especially in the case of sandblasted samples, the presence of peaks and valleys and indentation chipping was an important limitation for measuring correctly the indentation mark, affecting so the hardness measurement. In the AS, E, EI and EIT aged specimens, the value of hardness was similar, while it was higher in sandblasted-aged specimens, being the increase particularly marked in the $\mathrm{S}$ condition. Indentation cracks were clearly recognizable for the infiltrated materials, where crack opening displacement appeared to be enhanced, while they were difficult to observe for ST and ET conditions and were not detectable on S specimens. By contrast, in the AS, E and ET specimens, although cracks were not visible by LSCM, they could be detected with DIC illumination thanks to the relief associated with crack formation. This technique could not be applied in sandblasted materials because roughness was less uniform. To appreciate the different appearance, SEM images of ET and EIT indentation cracks, together with an optical image using differential interference contrast of an ET indentation crack, are shown in Fig. 6. 


\subsection{Aging behavior}

The monoclinic contents of AS, ST and ET specimens after artificial degradation were similar, about $45 \%$ (see Fig. 7). S specimens showed a moderate improvement in the aging resistance, while both SIT and EIT surfaces were fully resistant to LTD, proving the effectiveness of the infiltration method for avoiding this aging phenomenon. E specimens had the highest monoclinic phase content, meaning that the sole etching process decreases the stability of the surface. It is important to note that $\mathrm{S}$ and $\mathrm{E}$ specimens had already monoclinic phase contents of $12 \pm 2.3 \%$ and $11 \pm 1.4 \%$, respectively, before the aging treatment. The other samples were free from monoclinic phase prior to artificial aging.

\section{Discussion}

It has been shown that pressure infiltration of rough surfaces created by either etching or sandblasting is an effective method for superficially doping yttria-stabilized zirconia with Cerium oxide. This surface treatment may prevent hydrothermal degradation of zirconia dental parts without affecting the mechanical properties of the surface.

\subsection{Roughness analysis}

The two roughening treatments produce very different surfaces as shown in the topographic images of Fig. 1, nonetheless the $S_{a}$ values are approximately similar. However, for the $E$ surface it has to be taken into account that the nanometric roughness revealed by the SEM pictures of Figs. 4 and 5 may not be fully resolved by optical interferometry due to the limitation of the x-y resolution. The density of summits $S_{\mathrm{ds}}$ for the $\mathrm{E}$ surface is significantly higher than for the S surface, which can be explained by the different mechanism involved: in the sandblasting process, the distance between summits is likely to be related to the size of the Alumina particles used for blasting, whereas in the case of the etching process it is related to the random presence of pits. The higher value of $S_{d s}$ for the $E$ surface results in an expected higher value of $S_{d r}$. The latter is a measure of the specific surface and is a hybrid parameter, depending on both the amplitude (measured by parameters such as $S_{a}$, which is almost the same for both types of surface) and the frequency (measured by parameters such as $S_{\mathrm{ds}}$ ) of the features present on the surface. 
For the $\mathrm{S}$ surface, the thermal and infiltration treatments do not affect the density of summits $\mathrm{S}_{\mathrm{ds}}$ but induce a slight decrease of the average roughness $S_{\mathrm{a}}$, resulting in a decrease of $S_{\mathrm{dr}}$. By contrast, for the $E$ surface, the thermal and infiltration treatments induce a slight decrease of $S_{a}$ and a substantial decrease of $S_{d s}$, resulting in an important decrease of $S_{\mathrm{dr}}$. The changes observed in the roughness parameters in both cases can be

attributed to surface remodeling revealed by SEM pictures of Fig. 3 and Fig. 4 . Regarding the $S_{\text {ds }}$, the absence of change for the S surface and the substantial change for the E surface can be explained by the observation that in the S surface the summits are broader with respect to the $\mathrm{E}$ surface and therefore less affected by the remodeling process, since spaced peaks hardly join together. Overall, it can be concluded that the $\mathrm{S}$ surface is less affected by the TT and pressure infiltration. After the treatments, the $\mathrm{S}_{\mathrm{a}}$ parameter in SIT and EIT surfaces are similar, but the values of $S_{\mathrm{ds}}$ and $\mathrm{S}_{\mathrm{dr}}$ are rather different.

The roughness parameters measured with both roughening treatments after co-doping fall within the range of the ones observed in commercial dental implants with proved high success rate, both in terms of $S_{a}$ and $S_{d r}$ (Wennerberg and Albrektsson, 2009). This aspect suggests the potential of these surfaces for good osseointegration.

\subsection{Effect of the treatments on the surface}

The absence of color change in infiltrated samples could be related to the small concentration and limited thickness of the Ce enriched layer. This result may be relevant since the treatment does not interfere with the aesthetics in the case of dental crown and other visible parts. In contrast, 3Y-TZP materials doped with 2-7 mol \% of $\mathrm{CeO}_{2}$ by infiltration at the pre-sintered state (Camposilvan et al., 2015, 2012) and equally resistant to hydrothermal degradation had a marked yellow tonality.

A significant difference in the surface appearance of S and ST specimens is shown by SEM images of Fig. 2. As the surface of S specimens is highly deformed by the impacts, the treatment at high temperature is quite efficient in smoothing the asperities by recrystallization of the highly deformed superficial layer. On the contrary, the appearance of the surface is pretty similar between ST and SIT specimens, meaning that the presence of $\mathrm{CeO}_{2}$ has not markedly altered the surface profile, which is confirmed by the little variations of all the roughness parameters. At high magnification (see pictures 4 and 6), grains appear moderately enlarged for SIT specimens, while observing the FIB trench of Fig. 3 this enlargement seems to be limited to the very first 
layer of superficial grains. Ce co-doping is therefore modifying the microstructure of an extremely thin superficial layer of material, leaving unaltered the bulk. This qualitative observation is confirmed by the EDS $\mathrm{CeO}_{2}$ profile reported in Fig. 5, which indicates that the $\mathrm{CeO}_{2}$ content rapidly diminishes in the first 1-2 $\mu \mathrm{m}$ of material from about $5 \mathrm{~mol} \%$ to below $1 \mathrm{~mol} \%$, being the latter content not capable for modifying the microstructure and aging behavior of the base material, as it was shown in previous works for deeper codoping obtained through infiltration of porous preforms (Camposilvan et al., 2015). It is worth noting that a continuum $\mathrm{CeO}_{2}$ diffusion profile is obtained in the present work, so there is no sharp interface between $\mathrm{Y}$ TZP and Ce-Y-TZP that may alter the surface mechanical stability. Because of the small Ce co-doped thickness, the bulk mechanical properties cannot be affected. Near-surface mechanical properties might be influenced, but because of the limited amounts of ceria the influence is very weak. In fact, nanoindentation studies performed on polished 3Y-TZP after the diffusion of controlled amounts of $\mathrm{CeO}_{2}$, obtaining a similar concentration profile as for the present study (Marro et al., 2011), reported only a minor change in hardness and elastic modulus in the first $\sim 500 \mathrm{~nm}$ from the surface. Moreover, scratch testing performed in the same study showed a superior mechanical stability after hydrothermal exposure, comparable to non-aged 3Y-TZP. Therefore, the mechanical properties of infiltrated and not infiltrated materials are practically identical. No appreciable grain size variation is observed in association with the sole thermal treatment. In fact, by looking at Fig. 3-B and D, the bulk grains, which are not co-doped with Ce, appear to be of the same size. By adding Ce, grain growth is promoted by partially suppressing the solute drag mechanism active in Y-TZP, where yttria segregates at grain boundaries operating a drag force against their mobility (Boutz et al., 1994; Theunissen et al., 1992). The formation of large cubic grains after the decomposition of the supersaturated tetragonal phase in association with the local increase in stabilizer content is not to be excluded, although higher temperatures and longer times are normally required for the development of this bimodal grain distribution (Chevalier et al., 2004; Inokoshi et al., 2014).

It is significant that after doping, the grain size is still very similar to standard 3Y-TZP, meanwhile in Ce-TZP sintered with prealloyed powders containing typically $10-12 \mathrm{~mol} \% \mathrm{CeO}_{2}, 3-5 \mu \mathrm{m}$ grain sizes are usually reported (Tsukuma et al., 1985). Therefore, the microstructural change induced by infiltration is extremely limited in comparison with Ce-TZP. 
The EDS maps of Fig. 2 show that Ce is distributed over the entire surface. This result is surprising; in fact, due to the limited diffusion lengths of Cerium during the thermal treatment, it may be expected that it would accumulate in some spots where the salt would precipitate preferentially. This even distribution may arise on one hand from a very even initial salt precipitation and by its redistribution during drying, melting and decomposition into $\mathrm{CeO}_{2}$, when the formation of vapor deriving from the elimination of the solution and the hydration water would help in transporting the molten salt over uncovered regions. On the other hand, surface diffusion at the TT temperature, which represents a fast path for the movement of atoms, surely helps in increasing the diffusion length of the dopant, allowing reaching and modifying wider areas.

In acid etched specimens, the thermal treatment induces a clear change in the morphology of the surface. In the E specimens, the FIB trench of Fig. 5 reveals that the superficial porosity induced by preferential etching is less than $1 \mu \mathrm{m}$ deep, with pores of angular contour that reflects the shape of dissolved grains. At the same time, in addition to the grain-to-grain roughness created from the preferential etching, on the surface of each grain there is the presence of nanometric roughness since the etching process proceeds rather by pitting than uniformly inside the grains.

After the thermal treatment at $1450{ }^{\circ} \mathrm{C}$, the porosity almost disappears and the nanometric roughness is smoothed, since the superficial grains become rounded. The appearance of the surface is quite different when imaging from the top. The grain-to-grain roughness seems to be enhanced, maybe as a result of pores coalescence and material transport. The peak-to-valley difference is also higher with respect to the $\mathrm{E}$ condition. The grain size showed on FIB cross-sections is similar for E and ET specimens, showing the same tendency as for the sandblasted materials.

In EIT specimens, a further modification is introduced. From the top micrographs one appreciates an increase in grain size and a reduction of the number of valleys. By looking simultaneously at the FIB cross-section, the rounded and slightly enlarged shape of the outer grains is revealed. This must be related to the presence and diffusion of $\mathrm{CeO}_{2}$ during the thermal treatment, which seems to enhance the remodeling process at the surface. When Cerium nitrate decomposes into $\mathrm{CeO}_{2}$, this probably forms a layer that fills the open porosity, superficial cracks and defects. During the thermal treatment, this layer sinters together and to the zirconia substrate, diffusing into the host lattice, creating so the rounded contour. As a result, the integrity of the co- 
doped surface appears increased thanks to pore filling and grains rounding, which may be beneficial to reduce the risk of liberating debris into the body.

\subsection{Protection from degradation in infiltrated samples}

The important result of this work is that no monoclinic phase content measured by XRD was found in infiltrated materials, confirming therefore that the proposed treatment is absolutely effective for surface protection. AS, ST and ET specimens show the same aging behavior, meaning that the thermal treatment at $1450{ }^{\circ} \mathrm{C}$ removes any previous change in the surface that could affect its response to LTD. S specimens showed enhanced aging resistance with respect to the control ones, because of the compressive stresses introduced at the surface as a consequence of plastic deformation (Chintapalli, 2012; Kosmač, 2008), while E samples had poorer aging resistance. Since the monoclinic phase content of these two sets of samples was similar before artificial degradation (approximately $12 \%$ ), the higher monoclinic phase content of degraded E samples must be related to the lack of superficial compressive stresses plus, probably, the depletion of ions in superficial grains from the acid attack. The latter may have the double effect of destabilizing tetragonal phase due to the reduction in yttria content and favoring the diffusion of water species.

After artificial aging, no evidence of aging damage was found in FIB trenches milled from SIT material (see Fig. 3), in contrast with the ST and S material, where visible sub-superficial microcracks and damage interested a thickness of 2 to $3 \mu \mathrm{m}$. Monoclinic laths were also visible on the surface for the aged ST condition in many of the exposed grains (see detail of Fig. 2). A similar trend was found for the three acid etched surfaces. Aged ET specimens presented microcracks on the surface indicating that in this case particles may be released after long exposure to humid environment, which is potentially dangerous since this process could trigger chronic inflammation and osteolysis (Chevalier et al., 2007). The thickness of the degraded layer of aged ET specimens as measured from FIB trenches, was again of about 2-3 $\mu \mathrm{m}$. In this thickness, the presence of monoclinic laths and subsurface microcracks was clear. On the contrary, aged EIT specimens were completely free from microcracks. In the case of samples infiltrated at atmospheric pressure during preliminary studies, the presence of localized spots with evidence of aging may be the result of a not appropriate wetting of the whole surface as a result of air bubble trapping into valleys and pores. By performing pressure infiltration, the solution is capable for wetting the entire surface. Moreover, even if 
sporadic degraded spots were visible on trenches of the pressureless infiltrated material, the XRD results did not show the presence of any significant amount of monoclinic phase. Depending on the precise application, even though pressureless infiltration might work for improving the aging resistance, the application of pressure is recommended for avoiding localized and potentially dangerous phenomena.

The transformability of the superficial co-doped layer is affected in two ways by the presence of $\mathrm{CeO}_{2}$. On one hand the stability of the tetragonal phase is increased. It is well known that thanks to the oversized dimension of the $\mathrm{Ce}$ atom, which promotes a more symmetric coordination, the tetragonal structure is favored (Li et al., 1994). On the other hand, the observed grain size increase should reduce the tetragonal stability since bigger grains have a higher driving force for transformation, associated with an increase in tetragonal-tomonoclinic formation temperature (Becher and Swain, 1992).

With the presence of the sole $\mathrm{Y}^{3+}$ as stabilizer, the vacancies which are responsible for stabilizing the tetragonal phase are also responsible for the beginning of the degradation process. Water species can diffuse from the humid environment into the zirconia lattice, compensating the vacancies and destabilizing the tetragonal phase, which starts to transform. The key point is that since no vacancies are created for charge compensation when Ce is in the oxidized 4+ state, after the eventual $\mathrm{Y}_{2} \mathrm{O}_{3}$ vacancy suppression by diffusion of water species, the tetragonal phase at the surface is still stabilized by the presence of $\mathrm{CeO}_{2}$.

Although it is also well known that bigger grain sizes are generally more prone to degradation (Jue et al., 1991), here the limited grain size increase observed at the surface after the infiltration-diffusion treatment has a modest influence as compared to the stronger stabilizing effect of $\mathrm{CeO}_{2}$ addition.

The chart of Fig. 6 presents approximate values of the aged materials hardness. These results need a careful interpretation due to the presence of roughness, which does not allow an exact measurement. The depth of the $10 \mathrm{Kg}$ indentations is of $\sim 17 \mu \mathrm{m}$, therefore the thickness of tested material is much higher than the Ce enriched layer. The same hardness value is measured for AS and all the etched conditions, since etching does not introduce form or waviness on the surface nor plastic deformation, allowing an adequate measurement and proving that the HV10 hardness is not altered from infiltration nor thermal treatment.

On the contrary, sandblasted samples show higher values, which are the result of several factors. One is the non-planarity of the surfaces, which explains the slight increase for ST and SIT materials and the higher dispersion of the results. On the other hand, the presence of plastic deformation and compressive stresses after 
sandblasting may also contribute with a further increase. Chipping, as a consequence of residual lateral cracks produced by sandblasting, may also play a role reducing the apparent size of the indentation mark.

The measured c/a ratio is similar for AS and infiltrated specimens, meaning that there is no variation in indentation fracture toughness for all these specimens. By contrast, in S specimens no cracks or very short ones were found, because of the residual stresses present after sandblasting, which may approach values as high as $1 \mathrm{GPa}$ very close to the surface (Chintapalli et al., 2014). No significant differences were found in the c/a ratios of E, ET and EIT specimens after artificial aging, although indentation cracks were not easily visible in the first two cases and could be detected only by DIC. This is due to a reduced crack opening displacement as a consequence of the compressive surface layer associated with the $t-m$ transformation induced by hydrothermal degradation, confirming the XRD results. Even by SEM, the crack tip was difficult to determine as shown in Fig. 6-A, B and C. In the case of ST material, the DIC illumination did not help in measuring the whole crack length, so the apparent measured c/a ratio is lover, meanwhile cracks of length similar to SIT condition and smaller crack opening displacement are to be expected. The extreme dispersion of the ST data reflects the uncertainty in the determination of crack tip location in this case.

\subsection{Impact and perspectives}

It was proved that pressure infiltration of Cerium solutions on zirconia with rough surfaces is a valid method for preventing hydrothermal aging. The method can be also extended to CAD/CAM machined or ground zirconia parts, where a certain grade of roughness is present as a result of the machining process. Polished surfaces could also benefit from the treatment, eventually by selecting an appropriate additive that would increase the wettability and, at the same time, stick the solution to the surface during the drying and salt decomposition process. Another option is to dip the sintered parts directly into molten Cerium salts. In the latter case, the main problem could be related to the thickness of the molten salt coating and the generation of a too high quantity of $\mathrm{CeO}_{2}$ on the surface, which may not diffuse completely, resulting in lack of cohesion, or change completely the surface topology or microstructure generated by the roughening or machining/polishing process.

It is important to point out that the microstructural change is limited to a very thin layer and that mechanical properties cannot be affected by such a modification. Therefore, the same process could be attempted with 
other zirconia stabilizers which are able to form liquid solutions and precipitate in the form of sufficiently small particles or homogeneous films to allow complete diffusion into the zirconia surface. The key point of this process is that the active co-doping should interest a layer as thin as possible to not alter any other material property, but thick enough to cover the diffusion thickness of the water species coming from the environment. In this way, the lack of stabilizer in this region that arises from the annihilation of Oxygen vacancies is compensated, blocking in turn the next steps of low temperature degradation.

\section{Conclusions}

A step forward towards the establishment of reliable all-ceramic systems for dental restorations is presented in this paper. It was proved that the major downside of yttria-stabilized zirconia, represented by its susceptibility to hydrothermal aging, can be surmounted for roughened surfaces with the treatment proposed in this work. By pressure infiltration with a Cerium nitrate solution of sintered and roughened pieces, followed by a diffusion treatment, the aging resistance is dramatically improved. The Cerium co-doping affects only a superficial layer of a couple of micrometers in thickness, though the effect on the aging behavior is striking, since no monoclinic phase content is detected on the surface after long exposure to artificial degradation. At the same time, the final heat treatment reduces surface defects and residual stresses induced during the roughening process.

The proposed treatment influences the roughness, being the effect of surface remodeling more important in acid etched than in sandblasted specimens. However, in both cases final roughness parameters are suitable for adhesion purposes and promising for osseointegration.

The results of this study are directly applicable in the manufacturing of dental crowns, abutments and dentures. Moreover, this work sets the basis for further studies focused on cell and tissue response to the surfaces obtained by the proposed methods. In this way, stable and reliable dental implants could be developed. The method can potentially be extended to the design of other biomedical applications where structural materials have to be directly in contact with the bone or where surface roughness is needed. 


\section{Acknowledgements}

This work was supported by Ministry of Economy and Competitiveness (MINECO) under the project ref.

MAT2011-23913, the Government of Catalonia under the project ref. 2014 SGR 130 and the European

Commission under the $7^{\text {th }}$ Framework Programme (Marie Curie ITN 289958, Bioceramics for Bone Repair).

Erik Camposilvan acknowledges Universitat Politècnica de Catalunya for the grant FPU-UPC.

\section{References}

Bächle, M., Butz, F., Hübner, U., Bakalinis, E., Kohal, R.J., 2007. Behavior of CAL72 osteoblast-like cells cultured on zirconia ceramics with different surface topographies. Clin. Oral Implants Res. 18, 53-9. doi:10.1111/j.16000501.2006.01292.x

Becher, P.F., Swain, M. V., 1992. Grain-Size-Dependent Transformation Behavior in Polycrystalline Tetragonal Zirconia. J. Am. Ceram. Soc. 75, 493-502.

Boutz, M.M.R., Winnubst, A.J.A., Burggraaf, A.J., 1994. Yttria-Ceria Stabilized Tetragonal Zirconia Polycrystals: Sintering, Grain Growth and Grain Boundary Segregation. J. Eur. Ceram. Soc. 13, 89-102.

Boutz, M.M.R., Winnubst, A.J.A., Langerak, B., Olde Scholtenhuis, R., Kreuwel, K., Burggraaf, A., 1995. The effect of ceria co-doping on chemical stability and fracture toughness of Y-TZP. J. Mater. Sci. 30, 1854-1862.

Camposilvan, E., Garcia Marro, F., Mestra, Á., Anglada, M.J., 2015. Enhanced reliability of yttria-stabilized zirconia for dental applications. Acta Biomater. doi:10.1016/j.actbio.2015.01.023

Camposilvan, E., Marro, F.G., Mestra, A., Anglada, M., 2012. Development of a novel zirconia dental post resistant to hydrothermal degradation. IOP Conf. Ser. Mater. Sci. Eng. 31, 012016. doi:10.1088/1757-899X/31/1/012016

Casucci, A., Mazzitelli, C., Monticelli, F., Toledano, M., Osorio, R., Osorio, E., Papacchini, F., Ferrari, M., 2010. Morphological analysis of three zirconium oxide ceramics: Effect of surface treatments. Dent. Mater. 26, 751-60. doi:10.1016/j.dental.2010.03.020

Chevalier, J., Cales, B., Drouin, J.M., 1999. Low-Temperature Aging of Y-TZP Ceramics. J. Am. Ceram. Soc. 82, 2150 2154.

Chevalier, J., Deville, S., Münch, E., Jullian, R., Lair, F., 2004. Critical effect of cubic phase on aging in $3 \mathrm{~mol} \%$ yttriastabilized zirconia ceramics for hip replacement prosthesis. Biomaterials 25, 5539-45. doi:10.1016/j.biomaterials.2004.01.002

Chevalier, J., Gremillard, L., Deville, S., 2007. Low-Temperature Degradation of Zirconia and Implications for Biomedical Implants. Annu. Rev. Mater. Res. 37, 1-32. doi:10.1146/annurev.matsci.37.052506.084250

Chintapalli, R.K., 2012. Influence of sandblasting on zirconia in restorative dentistry. Universitat Politécnica de Catalunya.

Chintapalli, R.K., Marro, F.G., Jimenez-Pique, E., Anglada, M., 2013. Phase transformation and subsurface damage in 3Y-TZP after sandblasting. Dent. Mater. 29, 566-72. doi:10.1016/j.dental.2013.03.005 
Chintapalli, R.K., Mestra Rodriguez, A., Garcia Marro, F., Anglada, M., 2014. Effect of sandblasting and residual stress on strength of zirconia for restorative dentistry applications. J. Mech. Behav. Biomed. Mater. 29, 126-37. doi:10.1016/j.jmbbm.2013.09.004

Conrad, H.J., Seong, W.-J., Pesun, I.J., 2007. Current ceramic materials and systems with clinical recommendations: a systematic review. J. Prosthet. Dent. 98, 389-404. doi:10.1016/S0022-3913(07)60124-3

Cooper, L.F., Zhou, Y., Takebe, J., Guo, J., Abron, A., Holmén, A., Ellingsen, J.E., 2006. Fluoride modification effects on osteoblast behavior and bone formation at TiO2 grit-blasted c.p. titanium endosseous implants. Biomaterials 27, 926-36. doi:10.1016/j.biomaterials.2005.07.009

Denry, I., Kelly, J.R., 2008. State of the art of zirconia for dental applications. Dent. Mater. 24, 299-307. doi:10.1016/j.dental.2007.05.007

Dong, W., Sullivan, P., Stout, K., 1994. Comprehensive study of parameters for characterising three- dimensional surface topographyIII: Parameters for characterising amplitude and some functional properties. Wear 178, $29-43$. doi:10.1016/0043-1648(94)90127-9

Dong, W.P., Sullivan, P.J., Stout, K.J., 1994. Comprehensive study of parameters for characterising three-dimensional surface topography: IV: Parameters for characterising spatial and hybrid properties. Wear 178, 45-60.

Fischer, J., Grohmann, P., Stawarczyk, B., 2008. Effect of Zirconia Surface Treatments Zirconia / Veneering Ceramic Composites on the Shear Strength of 27, 448-454.

Gahlert, M., Röhling, S., Wieland, M., Eichhorn, S., Küchenhoff, H., Kniha, H., 2010. A comparison study of the osseointegration of zirconia and titanium dental implants. A biomechanical evaluation in the maxilla of pigs. Clin. Implant Dent. Relat. Res. 12, 297-305. doi:10.1111/j.1708-8208.2009.00168.x

Garvie, R.C., Hannink, R.H.J., Pascoe, R.T., 1975. Ceramic steel? Nature 258, 703-704. doi:10.1038/258703a0

Gruber, R., Hedbom, E., D. Bosshardt, D., Heuberger, R., Buser, D., 2012. Acid and alkali etching of grit blasted zirconia: Impact on adhesion and osteogenic differentiation of MG63 cells in vitro. Dent. Mater. J. 31, $1097-1102$. doi:10.4012/dmj.2012-107

Guo, X., 1998. Low temperature degradation mechanism of tetragonal zirconia ceramics in water: role of oxygen vacancies. Solid state ionics 112, 113-116.

Hempel, U., Hefti, T., Kalbacova, M., Wolf-Brandstetter, C., Dieter, P., Schlottig, F., 2010. Response of osteoblast-like SAOS-2 cells to zirconia ceramics with different surface topographies. Clin. Oral Implants Res. 21, $174-81$. doi:10.1111/j.1600-0501.2009.01797.x

Inokoshi, M., Zhang, F., De Munck, J., Minakuchi, S., Naert, I., Vleugels, J., Van Meerbeek, B., Vanmeensel, K., 2014. Influence of sintering conditions on low-temperature degradation of dental zirconia. Dent. Mater. 30, 669-78. doi:10.1016/j.dental.2014.03.005

Ito, H., Sasaki, H., Saito, K., Honma, S., Yajima, Y., Yoshinari, M., 2013. Response of osteoblast-like cells to zirconia with different surface topography. Dent. Mater. J. 32, 122-129. doi:10.4012/dmj.2012-208

Jevnikar, P., Sers, I., Sepe, A., Jarh, O., Funduk, N., 2000. Effect of Surface Coating on Water Migration Into ResinModified Glass Ionomer Cements : A Magnetic Resonance Micro-Imaging Study 691, 686-691.

Jue, J.F., Chen, J., Virkar, A. V., 1991. Low-Temperature Aging of t'-Zirconia: The Role of Microstructure on Phase Stability. J. Am. Ceram. Soc. 74, 1811-1820.

Kelly, J.R., Denry, I., 2008. Stabilized zirconia as a structural ceramic: an overview. Dent. Mater. 24, $289-298$. doi:10.1016/j.dental.2007.05.005 
Kern, M., Wegner, S.M., 1998. Bonding to zirconia ceramic: adhesion methods and their durability. Dent. Mater. 14, 6471. doi:10.1016/S0109-5641(98)00011-6

Kim, J.-W., Covel, N.S., Guess, P.C., Rekow, E.D., Zhang, Y., 2010. Concerns of hydrothermal degradation in CAD/CAM zirconia. J. Dent. Res. 89, 91-5. doi:10.1177/0022034509354193

Kosmač, T., 2008. The effects of dental grinding and sandblasting on ageing and fatigue behavior of dental zirconia (Y TZP) ceramics. J. Eur. Ceram. Soc. 28, 1085-1090. doi:10.1016/j.jeurceramsoc.2007.09.013

Lawn, B.R., 1993. Fracture of Brittle Solids, Second. ed. Cambridge Univ Press, Cambridge.

Li, P., Chen, I.-W., Penner-hahn, J.E., 1994. Effect of Dopants on Zirconia Stabilization-An X-ray Absorption Study: II, Tetravalent Dopants. J. Am. Ceram. Soc. 77, 1281-1288.

Lin, J.-D., Duh, J.G., 2003. Mechanical properties and resistance to hydrothermal aging of ceria-and yttria-doped tetragonal zirconia ceramics. Mater. Chem. Phys. 77, 808-818.

Marro, F.G., Valle, J., Mestra, a., Anglada, M., 2011. Surface modification of 3Y-TZP with cerium oxide. J. Eur. Ceram. Soc. 31, 331-338. doi:10.1016/j.jeurceramsoc.2010.10.008

Oliva, J., Oliva, M.S.X., Oliva, M.S.J.D., 2010. Five-year Success Rate of 831 Consecutively Placed Zirconia Dental Implants in Humans: A Comparison of Three Different Rough Surfaces. Int. J. Maxillofac. Implant. 25, 336-344.

Papanagiotou, H.P., Morgano, S.M., Giordano, R.A., Pober, R., 2006. In vitro evaluation of low-temperature aging effects and finishing procedures on the flexural strength and structural stability of Y-TZP dental ceramics. J. Prosthet. Dent. 96, 154-64.

Sato, T., Ohtaki, S., Fukushima, T., Endo, T., Shimada, M., 1987. Mechanical propierties and thermal stability of yttria doped tetragonal zirconia polycrystals with diffused ceria in the surface. Mater. Res. Soc. Symp. Proc. 78,147 154.

Theunissen, G.S.A.M., Winnubst, a. J. a., Burggraaf, a. J., 1992. Effect of dopants on the sintering behaviour and stability of tetragonal zirconia ceramics. J. Eur. Ceram. Soc. 9, 251-263. doi:10.1016/0955-2219(92)90060-Q

Toraya, H., Yoshimura, M., Somiya, S., 1984. Calibration Curve for Quantitative Analysis of the Monoclinic-Tetragonal ZrO2 System by X-Ray Diffraction. J. Am. Ceram. Soc. 67, C-119-C-121.

Tsukuma, K., Ueda, K., Matsushita, K., Shimada, M., 1985. High-Temperature Strength and Fracture Toughness of Y2O3-Partially-Stabilized ZrO2/A12O3 Composites. J. Am. Ceram. Soc. 68, C-56-C-58. doi:10.1111/j.11512916.1985.tb15284.x

Wennerberg, A., Albrektsson, T., 2009. On implant surfaces: a review of current knowledge and opinions. Int. J. Oral Maxillofac. Implants 25, 63-74.

Wenz, H.J., Bartsch, J., Wolfart, S., Kern, M., 2008. Osseointegration and Clinical Success of Zirconia Dental Implants: A Systematic Review. Int. J. Prosthodont. 21, 27-36.

Wolfart, M., Lehmann, F., Wolfart, S., Kern, M., 2007. Durability of the resin bond strength to zirconia ceramic after using different surface conditioning methods. Dent. Mater. 23, 45-50. doi:10.1016/j.dental.2005.11.040

Yamashita, D., Machigashira, M., Miyamoto, M., Takeuchi, H., Noguchi, K., Izumi, Y., Ban, S., 2009. Effect of surface roughness on initial responses of osteoblast-like cells on two types of zirconia. Dent. Mater. J. 28, 461-70. 
Table 1. Summary of specimens preparation treatments, performed in sequence from left to right.

Table 2. Brief description of the 3D roughness parameters studied (W. Dong et al., 1994; W. P. Dong et al., 1994).

Fig. 1. Roughness parameters of the studied materials. $S_{a}=$ average roughness, $S_{d r}=$ Developed Interfacial Area Ratio, $\mathrm{S}_{\mathrm{ds}}=$ Summit Density. On the right, topographic images of EIT and SIT surfaces are shown.

Fig. 2. Secondary electron images of the surface of S (A, B), ST (C, D) and SIT (E, F) materials after artificial degradation $(5 \mathrm{KV})$. In G, a BSE image (10 KV) of an area from the SIT sample is shown. $\mathrm{H}$ and I show respectively EDS maps of $\mathrm{Al}$ and $\mathrm{Ce}$ from the same area.

Fig. 3. FIB trenches of S material right after sandblasting (A and B, from published results (Chintapalli et al., 2013)) and of SIT material after artificial degradation (C and D). The focused ion image reveals the grains size.

Fig. 4. SEM Images of the surface of E (A and B), ET (C and D) and EIT (E and F) surfaces after artificial degradation. In D, arrows indicate the presence of LTD-induced microcracks.

Fig. 5. FIB trenches on $E$ sample right after etching ( $A$ and $B$ ) and after artificial degradation of ET (C and D) and EIT (E and F) specimens. $B$ is an ion image, while the rest are secondary electrons images of ion-etched surface. In image $\mathrm{E}$, the points correspond with the followings $\mathrm{CeO}_{2}$ contents (in $\mathrm{mol} \%$ ), as measured by EDS: a - 4.91, b - 0.96, c - 0.53, d - 0.38.

Fig. 6. Vickers Hardness and c/a ratio for the materials tested. Mean values + SD. To the right, the appearance of indentation cracks for ET condition by OM with DIC illumination (A), ET condition by SEM (B) and EIT condition by SEM (C). Arrows indicate the indentation corner and the tip of cracks observable on the picture.

Fig. 7. Monoclinic phase content after $30 \mathrm{~h}$ artificial degradation in autoclave (Mean values $+\mathrm{SD}$ ). Note that the monoclinic phase content in S samples was of $12 \pm 2.3 \%$ and in E samples was of $11 \pm 1.4 \%$ before the artificial aging treatment. 


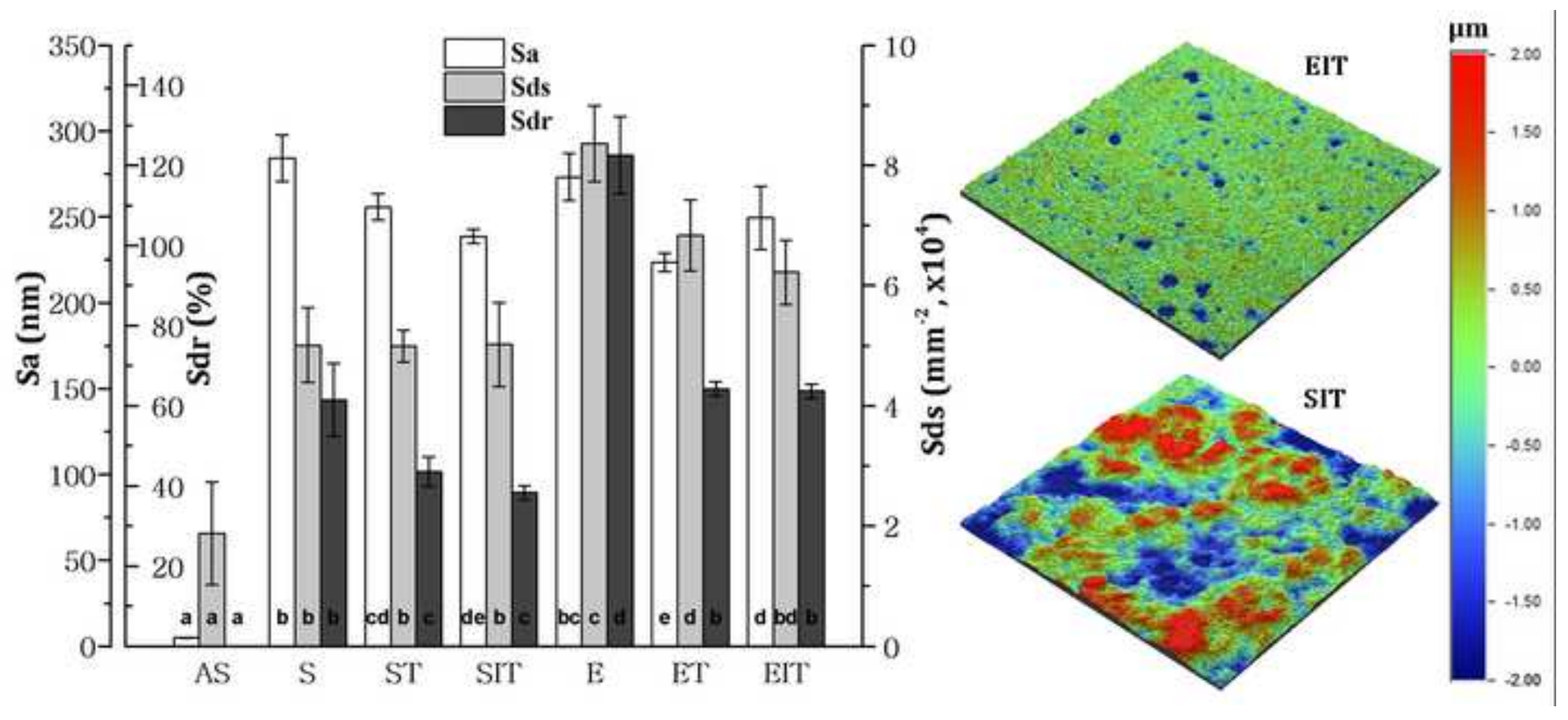


Flick here to download high resolution image
Clice 2 Revised
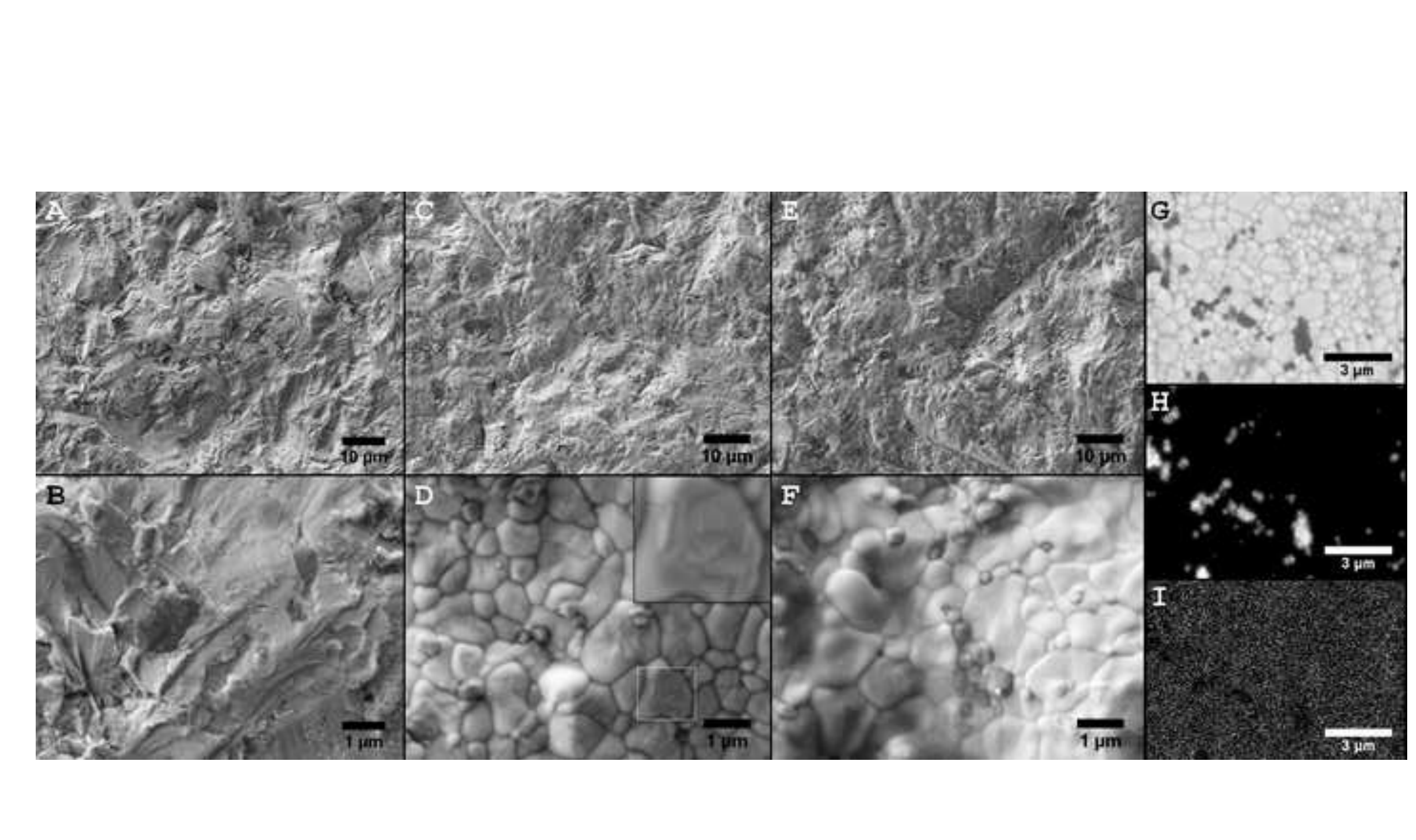

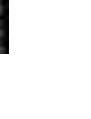




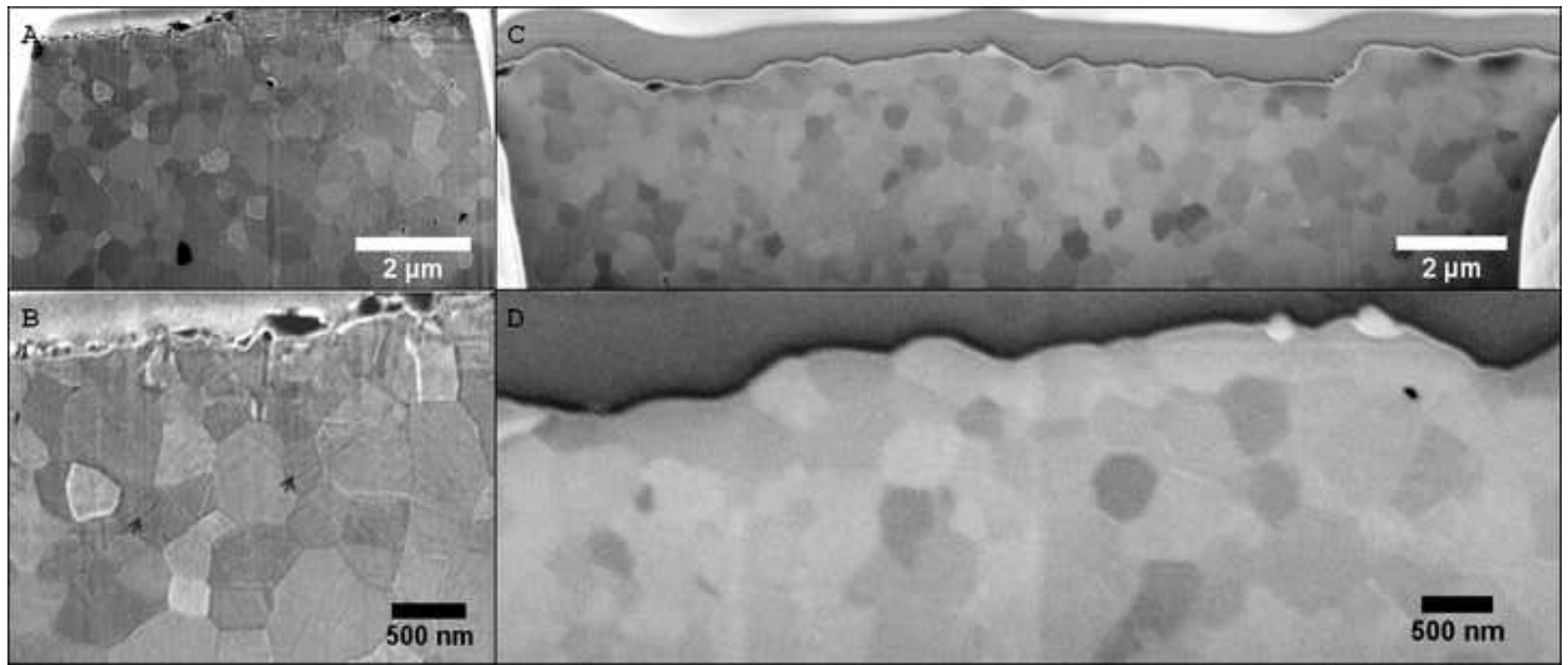


Figure4

Click here to download high resolution image

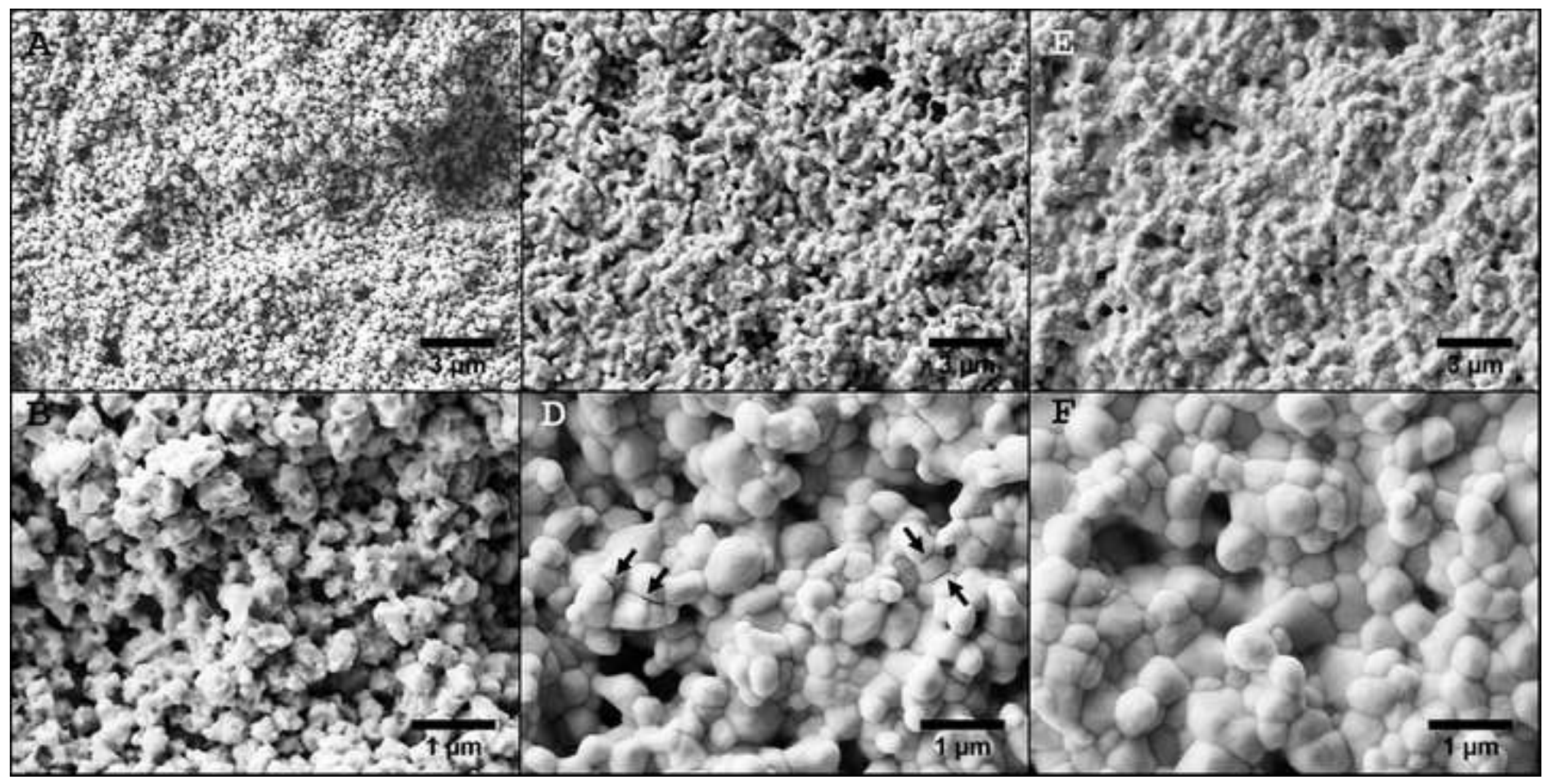


Figure5
Click here to download high resolution image

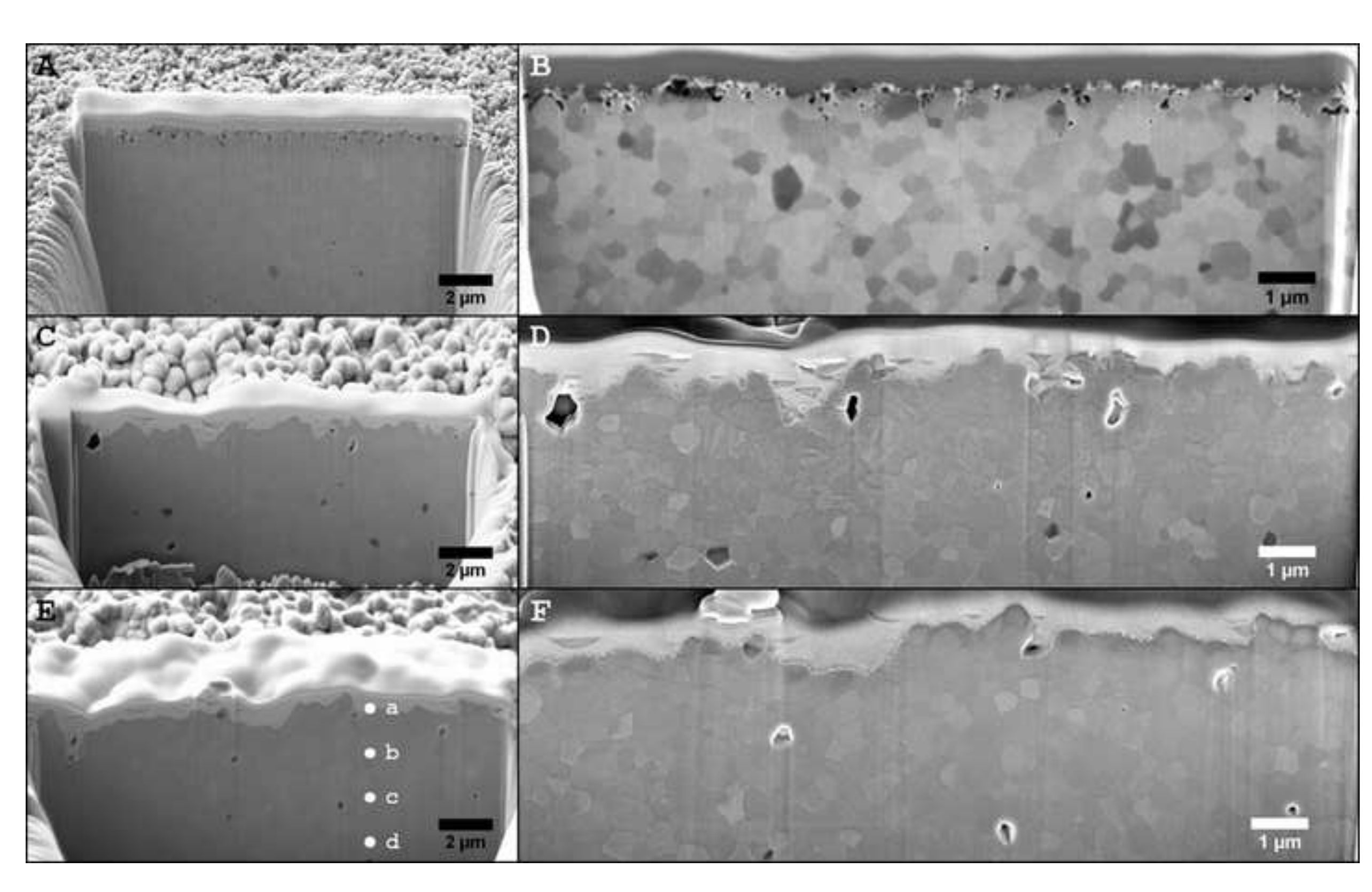


Click here to download high resolution image

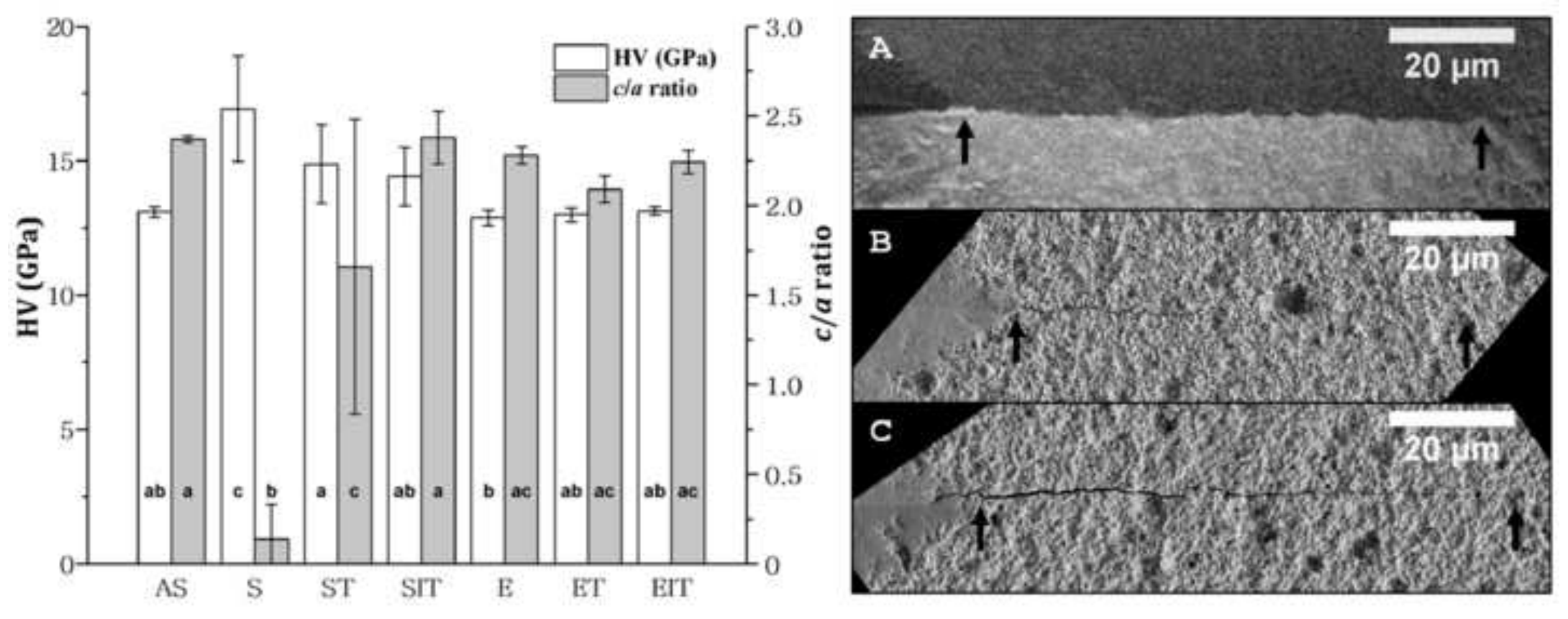




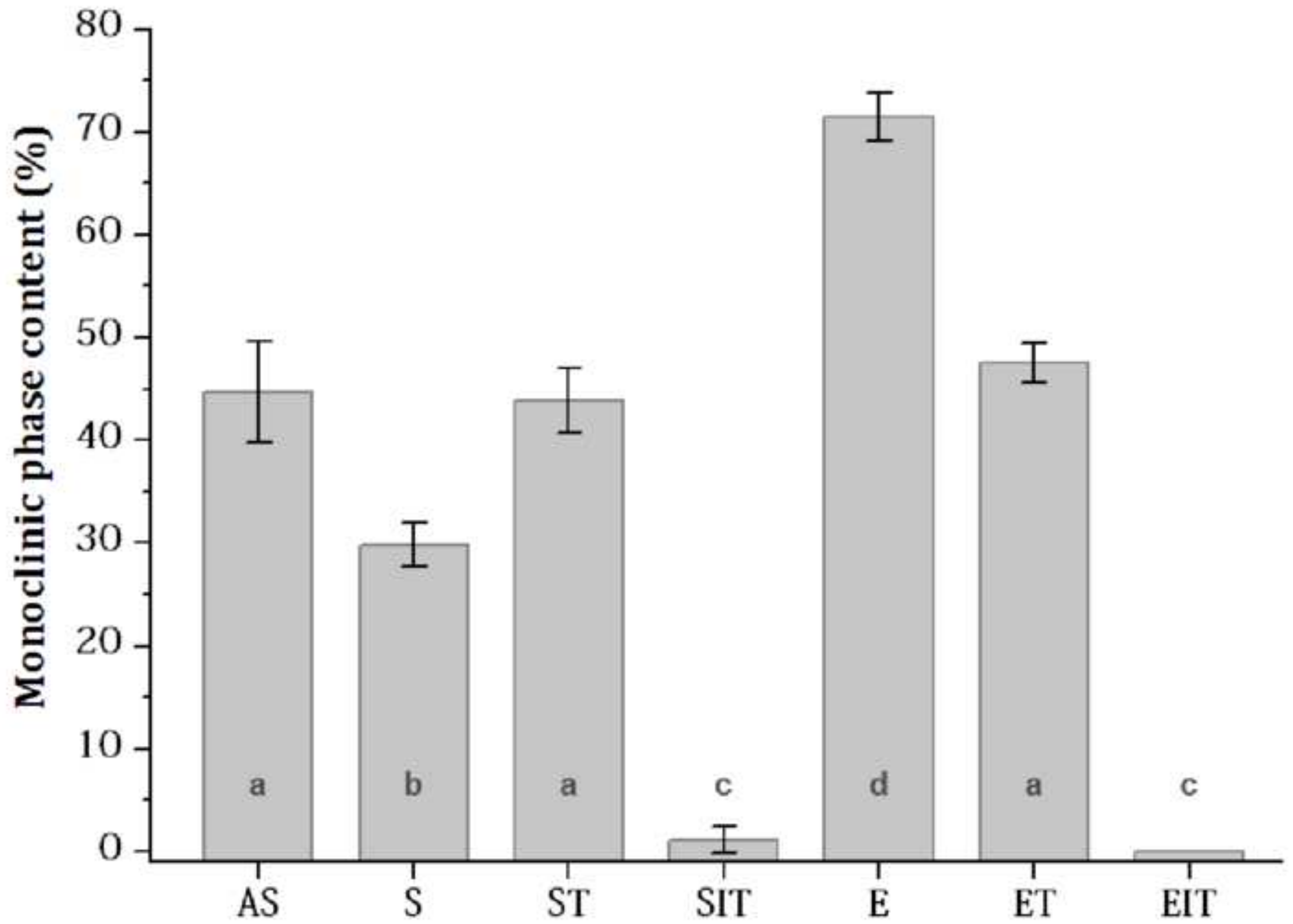




\begin{tabular}{llllll}
\hline Material & Sint. $1450^{\circ} \mathrm{C}$ & Sandblast. & \multirow{2}{*}{ A. Etching $1 \mathrm{~h}$} & $\begin{array}{l}\text { Inf.50MPa } \\
10 \mathrm{~s}\end{array}$ & $\begin{array}{l}\text { TT } 1450^{\circ} \mathrm{C} \\
1 \mathrm{~h}\end{array}$ \\
\hline AS-control & $\checkmark$ & 10 polished & 1 & & \\
S & $\checkmark$ & & & & $\checkmark$ \\
ST & $\checkmark$ & $\checkmark$ & $\checkmark$ & $\checkmark$ \\
SIT & $\checkmark$ & $\checkmark$ & & \\
E & $\checkmark$ & $\checkmark$ & & $\checkmark$ \\
ET & $\checkmark$ & $\checkmark$ & $\checkmark$ & $\checkmark$ \\
EIT & $\checkmark$ & & $\checkmark$ & & \\
\hline
\end{tabular}




\begin{tabular}{|c|c|c|c|}
\hline Symbol & Category & Parameter & Description \\
\hline $\mathrm{Sa}$ & Amplitude & Average roughness & Average of height values \\
\hline$S_{\mathrm{d} z}$ & Spatial & Density of summits & Number of summits per unit area \\
\hline$S_{\text {d }}$ & Hybrid & $\begin{array}{l}\text { Developed } \\
\text { interfacial area ratio }\end{array}$ & $\begin{array}{l}\text { Percentage of additional surface area contributed by the texture } \\
\text { as compared to an ideal plane the size of the measurement region }\end{array}$ \\
\hline
\end{tabular}



Supplementary Material for on-line publication only
Click here to download Supplementary Material for c Click here to download Supplementary Material for on-line publication only: Supporting Information.docx $=x$ (a) (1) (a) pex (1)

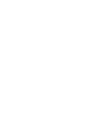
(2) (2)

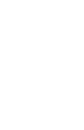

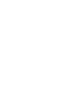

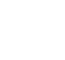
.

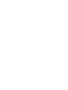

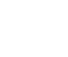

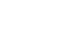

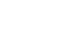

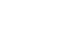

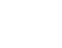

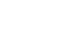

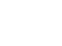

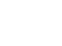

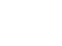

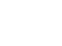

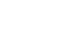

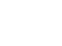

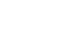

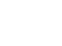

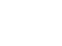

